\title{
Effects of 24-week treatment with acarbose on glucagon-like peptide 1 in newly diagnosed type 2 diabetic patients: a preliminary report
}

Miao-yan Zheng, Ju-hong Yang, Chun-yan Shan, Hong-tao Zhou, Yan-guang Xu, Ying Wang, Hui-zhu Ren, Bao-cheng Chang ${ }^{*}$ and Li-ming Chen ${ }^{*}$

\begin{abstract}
Background: Treatment with the alpha-glucosidase inhibitor (AGI) acarbose is associated with a significant reduction the risk of cardiovascular events. However, the underlying mechanisms of this effect are unclear. AGls were recently suggested to participate in stimulating glucagon-like peptide 1 (GLP-1) secretion. We therefore examined the effects of a 24-week treatment of acarbose on endogenous GLP-1, nitric oxide (NO) levels, nitric oxide synthase (NOS) activity, and carotid intima-media thickness (CIMT) in newly diagnosed patients with type 2 diabetes (T2D).

Methods: Blood was drawn from 24 subjects (14 male, 10 female, age: $50.7 \pm 7.36$ years, BMl: $26.64 \pm 3.38 \mathrm{~kg} / \mathrm{m}^{2}$, GHbA1c: $7.00 \pm 0.74 \%$ ) with drug-naïve T2D at 0 and 120 min following a standard mixed meal for the measurements of active GLP-1, NO and NOS. The CIMT was measured prior to and following 24 weeks of acarbose monotherapy (mean dose: 268 mg daily).

Results: Following 24 weeks of acarbose treatment, both fasting and postprandial plasma GLP-1 levels were increased. In patients with increased postprandial GLP-1 levels, serum NO levels and NOS activities were also significantly increased and were positively related to GLP-1 levels. Although the CIMT was not significantly altered following treatment with acarbose, a decreased CIMT was negatively correlated with increased GLP-1 levels.

Conclusions: Twenty-four weeks of acarbose monotherapy in newly diagnosed patients with T2D is associated with significantly increased levels of both fasting and postprandial GLP-1 as well as significantly increased NO levels and NOS activity for those patients in whom postprandial GLP-1 levels were increased. Therefore, the benefits of acarbose on cardiovascular risk may be related to its stimulation of GLP-1 secretion.
\end{abstract}

Keywords: Glucagon-like peptide 1, Carotid intima-media thickness, Nitric oxide type 2 diabetes, Acarbose

\section{Background}

Type 2 diabetes (T2D) is known to dramatically increase the risk of cardiovascular disease, such as angina pectoris and myocardial infarction, and it is believed that hyperglycemia itself, especially postprandial hyperglycemia, is an independent risk factor for such diseases [1-4]. The previous studies have shown that treatment with acarbose, an alpha-glucosidase inhibitor (AGI), is associated with a significant reduction in cardiovascular

\footnotetext{
* Correspondence: changbc1970@126.com; xfx22081@vip.163.com
Key Laboratory of Hormone and Development (Ministry of Health), Metabolic

* Correspondence: changbc1970@126.com; xfx22081@vip.163.com
Key Laboratory of Hormone and Development (Ministry of Health), Metabolic Disease Hospital \& Tianjin Institute of Endocrinology, Tianjin Medical University, Tianjin 300070, China
}

events in a population with T2D and impaired glucose tolerance (IGT) [5,6]. However, the underlying mechanisms of this effect are unclear. Recently, new insights into the possible actions of acarbose on cardiovascular risks have been provided by the incretin concept. Following the intake of AGIs, large amounts of undigested carbohydrates reach the lower portion of the small intestine, which is rich in L-cells that produce glucagon-like peptide 1 (GLP-1) and therefore stimulate a long-lasting increased secretion of GLP-1 $[7,8]$. GLP-1 can elevate levels of nitric oxide (NO), which is the most important endothelium-derived vasodilator and has a potent antiatherosclerotic effect $[9,10]$ in the coronary effluent from 
mouse hearts [11]. Moreover, a recent animal study suggests that voglibose (another AGI) can reduce myocardial infarct size through the stimulation of GLP-1 receptors and the activation of the phosphoinositide 3-kinase-Aktendothelial NOS pathways [12].

To date, the majority of studies have evaluated the short-term effects of acarbose treatment (up to 2 weeks) on GLP-1; the long-term effects of AGIs on NO and NOS in T2D have not been extensively investigated. In the present study, we aimed to explore whether levels of serum GLP-1 and NO and NOS activity increase following chronic (24 weeks) treatment with acarbose monotherapy in newly diagnosed patients with T2D. We also aimed to evaluate the effect of acarbose on carotid atherosclerosis (as defined by carotid intima-media thickness [CIMT]). It is known that CIMT has an important prognostic value with respect to the development of both cardiovascular diseases and of atherosclerotic lesions in the carotid and peripheral arteries $[13,14]$.

\section{Methods \\ Subjects}

This was a prospective, observational study of patients with drug-naive T2D who were commencing acarbose as a monotherapy. Newly diagnosed patients with T2D (aged 30-70 years) who met the World Health Organization diagnostic criteria [15] were recruited from the diabetic outpatient clinic in the Metabolic Disease Hospital of Tianjin Medical University between October 2011 and June 2012. The exclusion criteria were glycosylated hemoglobin Alc (HbA1c >9\%), a history of congestive heart failure (NYHA Class III or IV), or severe hepatic (serum alanine or aspartate aminotransferase $>100 \mathrm{U} / \mathrm{L}$ ) or renal disease (estimated creatinine clearance $<60 \mathrm{ml} / \mathrm{min}$ ). The patients with current malignant disease, inflammatory bowel disease, those who were pregnant, women who were breast-feeding and patients who had a history of major psychiatric disease were also excluded. Lifestyle intervention was recommended to all of the eligible patients by the diabetic educator. The patients were also excluded if their blood glucose was restored to normal following 1 month of lifestyle intervention. The study protocol was approved by the Tianjin Medical University Ethics Committee Review Board and was conducted using Good Clinical Practice in accordance with the Declaration of Helsinki. All of the participants provided informed consent.

\section{Study protocol}

On the morning of the first visit (V1), following an overnight fasting for 12-14 $\mathrm{h}$, the patients were asked to attend the investigational unit. The anthropometric assessments were performed, including body mass index (BMI) and blood pressure. The blood was drawn at 0 and 120 min following breakfast (the meal was ingested within 10-15 min) for the measurements of plasma active GLP-1, serum insulin NO and NOS activity, and glycated hemoglobin A1c (GHbA1c). Fasting plasma glucose (FPG) and $2 \mathrm{~h}$ postprandial plasma glucose (P2PG) levels were also determined. The breakfast was a standard mixed meal that provided approximately $380 \mathrm{kcal}$, and the energy load was calculated to be $16.0 \%$ fat, $9.5 \%$ protein and $74.5 \%$ carbohydrate. The blood samples were taken and immediately cooled and centrifuged at 4. C. The plasma was stored at $-80^{\circ} \mathrm{C}$ until analysis. The blood samples for the determination of active GLP-1 were collected into tubes that contained heparin anticoagulant and $0.1 \mathrm{mmol} / \mathrm{L}$ sitagliptin phosphate (Beijing HuiKang BoYuan Chemical Tech CO., LTD, Beijing, China) to prevent degradation by the dipeptidyl peptidase- 4 (DPP-4) enzyme. Next, the CIMT was measured for all of the patients.

Following V1, the patients were commenced on acarbose tablets (Glucobay ${ }^{\circledR}$; Bayer AG, Leverkusen, Germany), beginning at $75 \mathrm{mg}$ daily. The dose was titrated upwards over a period of 4-18 weeks to the dose that produced satisfactory metabolic control or to the maximum dose that was tolerated by the patient. The acarbose tablets were taken with the first bite of the meal, and the maximum given dose was $300 \mathrm{mg}$ daily. The subjects who experienced gastrointestinal side effects during the period of upward titration were instructed to return to the previously tolerated dose for a further 2 weeks and then to attempt to increase the dosage again if the lower dose was tolerated. During this time, all of the patients were instructed to continue with their diet as previously recommended.

Following V1, the participants were asked to again visit the investigational site on the 4th (V2), 8th (V3), 12th (V4), and 18th week (V5) of the study. On these days, the blood glucose levels were determined, lifestyle advice was offered (as in routine clinical practice), compliance with medication was assessed and further dose titration was recommended, as appropriate. All of the subjects attended the visits at 6 and 24 weeks following the initiation of acarbose monotherapy, and the procedures that were described for V1 were repeated. Telephone contact was maintained with all of the subjects between V1 and V6 to monitor their compliance with the medication and to offer advice regarding problems with medication tolerance.

\section{Laboratory measurements}

Both fasting and $2 \mathrm{~h}$ postprandial active GLP-1 levels [GLP-1 (7-36) and (7-37)] were determined using commercial enzyme-linked immunoassay (ELISA) kits from Millipore (Billerica, MA, USA). The detection limit of the ELISA was $2 \mathrm{pmol} / \mathrm{L}$, with an intra-assay coefficient of variation $(\mathrm{CV})$ of $7.8 \% \sim 9.9 \%$ and interassay $\mathrm{CV}$ of 
$8.1 \% \sim 10.8 \%$. The serum NO activity was detected using the nitrate reductase method with the NO Kit (Nanjing Jiancheng BioEngineering Co., Ltd., Nanjing, China). The generation of $\mathrm{NO}$ was determined by measuring the release of nitrite $\left(\mathrm{NO}_{2}^{-}\right.$and $\left.\mathrm{NO}_{3}^{-}\right)$, which is the stable oxidation product of NO. The NOS kit (Nanjing Jiancheng BioEngineering Co., Ltd., Nanjing, China) was used to measure the activity of NOS in the plasma, in which NOS produces NO from L-arginine and oxygen in addition to two iron complexes (the color reagent), which form a colored material. The absorbance is then measured at a wavelength of $540 \mathrm{~nm}$, and the extinction coefficient used to calculate NOS activity. The serum insulin concentration was analyzed using the Roche E170 electrochemiluminescence immunoassay [Elecsys 2012 insulin kit (Ref12017547), Roche Diagnostics GmbH, Indianapolis, IN, USA].

\section{Carotid ultrasonography measurements}

The carotid arteries were assessed using high-resolution B-mode ultrasonography using GE Logiq 7 ultrasound with a $10-\mathrm{MHz}$ high-resolution transducer (General Electric, Wauwatosa, WI, USA). All of the measurements were performed by a single ultrasonographer using the same equipment and were assessed by a single reader who was blinded to the study question, patient, and follow-up time point. A rapid cross-sectional scanning was performed as a first step to pinpoint the location of the possible plaques. The scan was begun from the proximal portion of the common carotid artery (CCA) toward the bifurcation, followed by a scan of the internal and then the external carotid arteries. This process was followed by a longitudinal scanning of the CCA. A segment of the artery (generally where the vessel walls were most clearly discerned throughout the recording) was magnified to identify a distinct lumen-intima and media-adventitia interface. The CIMT was defined as the distance between the leading edge of the lumen-intima interface and the leading edge of the media-adventitia interface. The regions of interest were defined as $1.0 \mathrm{~cm}$ distal to the bifurcation, the bifurcation and $1.0 \mathrm{~cm}$ proximal to the internal carotid artery in both near and far walls. Next, for each subject, the mean CIMT was reported as the average of 10 measurements ( 5 measurements from the right and 5 from the left carotid artery).

\section{Statistical analysis}

The data are expressed as the means and the standard deviation or as numbers and percentages. As the levels of serum insulin were markedly skewed, natural logarithm -transformed values were used. The differences in CIMT, anthropometric and laboratory parameters from baseline to the endpoint were compared using a 2-tailed paired t-test. Pearson correlation analysis was used to assess possible relationships between alterations of plasma GLP-1 and NO levels, CIMT and other laboratory data. The analyses were performed using SPSS windows version 17.0 , and $p<0.05$ was considered to be statistically significant.

\section{Results}

A total of 26 patients entered the trial, 24 (92.3\%) of whom completed the trial. Two patients dropped out the study (one was not able to tolerate the abdominal distension and anal exhaust and dropped out at V2, the other patient was lost of follow up at V3 for unknown reasons). The mean age of the 24 subjects (14 male, 10 female) was $50.7 \pm 7.36$ years. The mean dose of acarbose at visit 6 was $268 \mathrm{mg}$ daily (range: $150-300 \mathrm{mg}$ daily). Glycemic control improved in all of the patients following 6 months of acarbose therapy. However, there was no significant change in body weight or BMI (Table 1).

\section{Plasma GLP-1 and serum insulin levels Plasma GLP-1}

Following 24 weeks of acarbose monotherapy, the fasting plasma GLP-1 levels increased from $4.92 \pm 0.94 \mathrm{pmol} / \mathrm{L}$ (pre-treatment) to $5.46 \pm 1.28 \mathrm{pmol} / \mathrm{L}$ (post-treatment) $(P<0.05)$. The $2 \mathrm{~h}$ postprandial GLP-1 levels increased from $5.23 \pm 1.26 \mathrm{pmol} / \mathrm{L}$ (pre-treatment) to $6.26 \pm 1.64 \mathrm{pmol} / \mathrm{L}$ (post-treatment, $P<0.05$, Figure $1(1)$ ).

\section{Serum insulin}

The mean $2 \mathrm{~h}$ postprandial serum insulin (natural logarithm-transformed) levels were significantly reduced

Table 1 Changes in glycemic control and body weight with acarbose treatment

\begin{tabular}{ccccc}
\hline Variable & Pre-treatment & Post-treatment & Mean changes from baseline (95\%Cl) & $\boldsymbol{p}$-value \\
\hline GHbA1c (\%) & $7.00 \pm 0.74$ & $6.18 \pm 0.51$ & $-0.82(-1.23,-0.41)$ & 0.000 \\
FPG (mmol/L) & $8.31 \pm 0.93$ & $7.20 \pm 0.85$ & $-1.11(-1.56,-0.66)$ & 0.000 \\
P2PG (mmol/L) & $14.34 \pm 2.65$ & $10.10 \pm 1.12$ & $-4.25(-5.56,-2.94)$ & 0.000 \\
Weight $(\mathrm{kg})$ & $74.71 \pm 12.30$ & $74.96 \pm 11.70$ & $-0.25(-0.78,0.28)$ & 0.341 \\
BMl $\left(\mathrm{kg} / \mathrm{m}^{2}\right)$ & $26.64 \pm 3.38$ & $26.64 \pm 0.38$ & $-0.10(-0.29,0.09)$ & 0.279 \\
\hline
\end{tabular}

Data are expressed as mean \pm S.D; HbA1c: glycated haemoglobin A1c; FPG: fasting plasma glucose; P2PG: 2 hour postprandial plasma glucose; BMI: body mass index. 


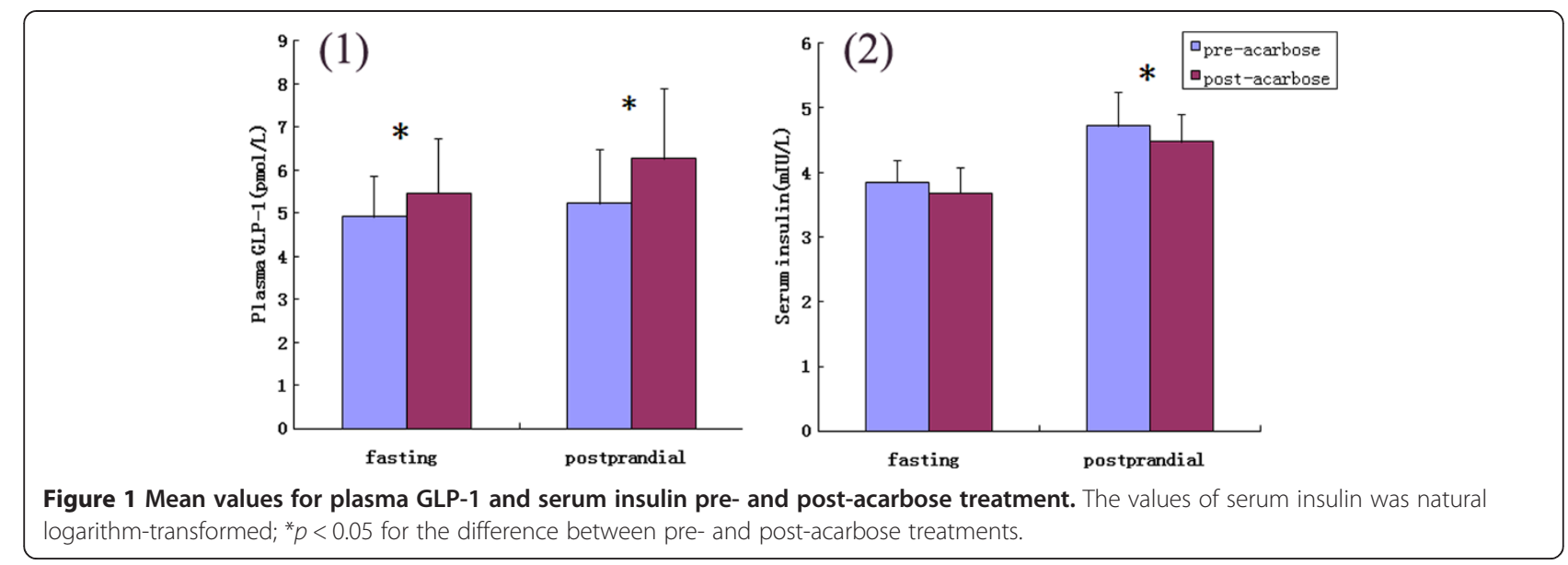

following acarbose treatment (post-treatment: $4.48 \pm$ $0.42 \mathrm{mIU} / \mathrm{L}$ vs. pre-treatment $4.72 \pm 0.53 \mathrm{mIU} / \mathrm{L}, p=0.041$ ). The mean fasting insulin (natural logarithm-transformed) levels were marginally reduced following the 24-week treatment period, but this difference was not statistically significant (post-treatment: $3.68 \pm 0.40 \mathrm{mIU} / \mathrm{L}$ vs. pre-treatment: $3.85 \pm 0.35 \mathrm{mIU} / \mathrm{L}, \mathrm{P}=0.064$, Figure $1(2)$ ).

\section{Serum NO levels and NOS activity}

Both the serum NO levels and NOS activity were marginally increased following the 24-week acarbose treatment; however, these changes were not statistically significant (post-treatment NO $49.90 \pm 25.07 \mu \mathrm{mol} / \mathrm{L}$, NOS activity $32.49 \pm 2.34 \mathrm{U} / \mathrm{ml}$ vs. pre- treatment $\mathrm{NO}$ $47.48 \pm 24.18 \mu \mathrm{mol} / \mathrm{L}, \mathrm{NOS}$ activity $31.75 \pm 2.83 \mathrm{U} / \mathrm{ml}$, $\mathrm{P}>0.05$, Figure $2(1,2) \mathrm{A})$. We further divided the patients into the following subgroups according to the observed changes in fasting or $2 \mathrm{~h}$ postprandial plasma
GLP-1 levels: fasting GLP-1 increased group ( $\mathrm{n}=17)$ vs. decreased group $(n=7)$, and postprandial GLP-1 increased group $(n=18)$ vs. decreased group $(n=6)$. We observed that both the serum NO levels and NOS activities were significantly increased following acarbose treatment for those in the postprandial GLP-1 increased subgroup (postacarbose NO $50.78 \pm 19.28 \mu \mathrm{mol} / \mathrm{L}$, NOS activity $32.76 \pm$ $2.40 \mathrm{U} / \mathrm{ml}$ vs. pre-acarbose $\mathrm{NO} 46.61 \pm 18.49 \mu \mathrm{mol} / \mathrm{L}$, NOS activity $31.21 \pm 2.50 \mathrm{U} / \mathrm{ml}, \mathrm{P}<0.05$, Figure $2(1,2) \mathrm{C}$ ). No such significant change was observed for those in the postprandial GLP-1 decreased subgroup ( $\mathrm{P}>0.05$, Figure 2 $(1,2) B)$. There were no significant changes for the fasting GLP-1 increased or decreased subgroups $(\mathrm{P}>0.05$, data not shown).

\section{CIMT}

The mean CIMT was not significantly different following 24 weeks of acarbose monotherapy $(P>0.05$, Figure 2 (3)A).

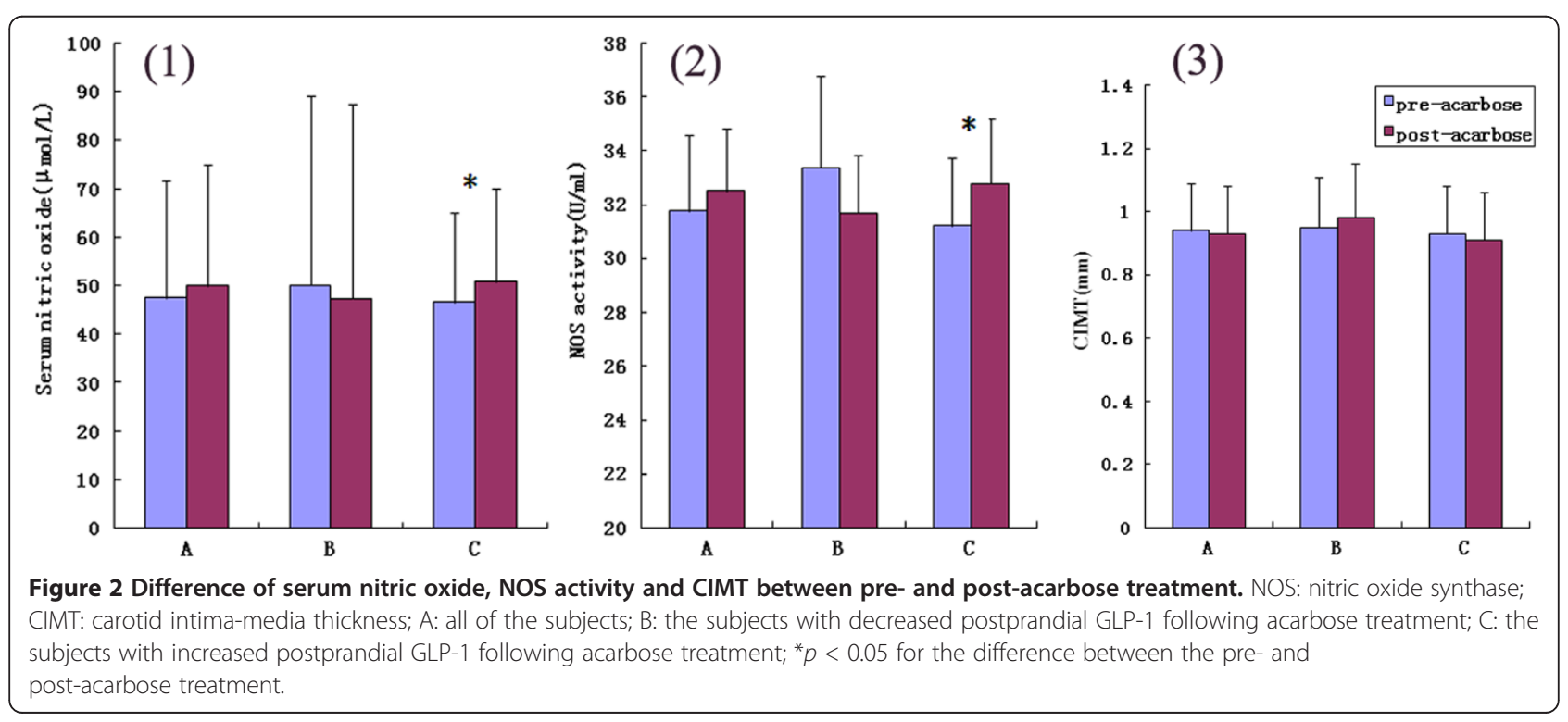


Moreover, the pre- and post-acarbose treatment CIMTs were not significantly different for either the fasting GLP1decreased/increased subgroups (data not shown) or for the postprandial GLP-1 decreased/increased subgroups $(P>0.05$, Figure $2(3) \mathrm{B}, \mathrm{C})$.

\section{The correlation between the changes in GLP-1, NO, CIMT and other laboratory data with acarbose treatment}

Increased values of fasting GLP-1 were negatively correlated with a change in GHbA1c levels ( $R$ value: -0.491 ; $\mathrm{P}<0.05)$. Moreover, increased $2 \mathrm{~h}$ postprandial GLP-1 levels were negatively correlated with the changes of GHbA1c, FPG and the mean CIMT ( $R$ values: $-0.636,-0.481$ and -0.628 , respectively; $\mathrm{P}<0.05)$ and positively correlated with the changes of NO and NOS ( $R$ values: 0.452 and 0.561 , respectively; $\mathrm{P}<0.05$ ). The changes in the mean CIMT were negatively correlated with changes in NO levels $(R$ value: $-0.577 ; \mathrm{P}<0.05)$ but not with changes in NOS activity ( $R$ value: $-0.314 ; \mathrm{P}=0.135$ ). Furthermore, the changes in NO levels and NOS activity were positively correlated $(R$ value: $0.449 ; \mathrm{P}<0.05)$ (Table 2$)$.

\section{Discussion}

Our study indicates that chronic acarbose therapy is associated with a significant increase in both fasting and postprandial active GLP-1 levels in newly diagnosed patients with T2D. What's more, our study provides evidence that postprandial GLP-1 increment after acarbose treatment is closely correlated with increment of $\mathrm{NO}$ levels and NOS activity and also with reduction of the mean CIMT. This is, to the best of our knowledge, the first study to investigate the long term effect of AGIs on GLP-1, NO secretion, NOS activity and its association with improved atherosclerosis in newly diagnosed patients with T2D.
Effects of acarbose on plasma GLP-1 and insulin level

We demonstrated that, in newly diagnosed patients with T2D, chronic acarbose therapy is associated with a significant increase in both fasting and postprandial active GLP-1 concentrations in addition to good glycemic control, as expected. These results are consistent with other studies that have reported increased postprandial GLP-1 levels following administration of either (i) following a single dose of acarbose or following 2 weeks of acarbose treatment in both normal subjects and those with T2D $[7,8,16,17]$, or (ii) acarbose in combination with alogliptin (a DPP-4 inhibitor) [18]. This effect is most likely due to a reduction in carbohydrate absorption in the proximal portion of the small bowel, increasing the load of these nutrients in the distal intestine, where GLP-1 secretion is greater. Unlike previous studies, we demonstrated this effect following long-term (24 weeks) therapy, highlighting yet another important aspect of the glucose-lowering properties of acarbose among new diagnosed patients with T2D. In the present study, we first report that fasting active GLP-1 levels are significantly elevated following 24 weeks of acarbose treatment. As previously reported, the functional integrity of GLP-1-secreting cells is seriously impaired even in the context of mild diabetes, and GLP-1 is deficient in patients with T2D $[19,20]$. Our data indicate that increased fasting GLP-1 levels are negatively correlated with changes of GHbA1c and that increased $2 \mathrm{~h}$ postprandial GLP-1 levels are negatively correlated with the observed changes in both GHbA1c and FPG (Table 2). These results suggest that glycemic control following a 24-week treatment with acarbose may contribute in part to the restoration of the GLP-1 secretion defect in newly diagnosed patients with T2D. Previous studies have focused on the effect of GLP-1 following either a single dose of acarbose or a brief treatment period (i.e., not more than 2 weeks), and only changes in postprandial

Table 2 Correlations between changes in GLP-1, NO, CIMT and other laboratory data following acarbose treatment

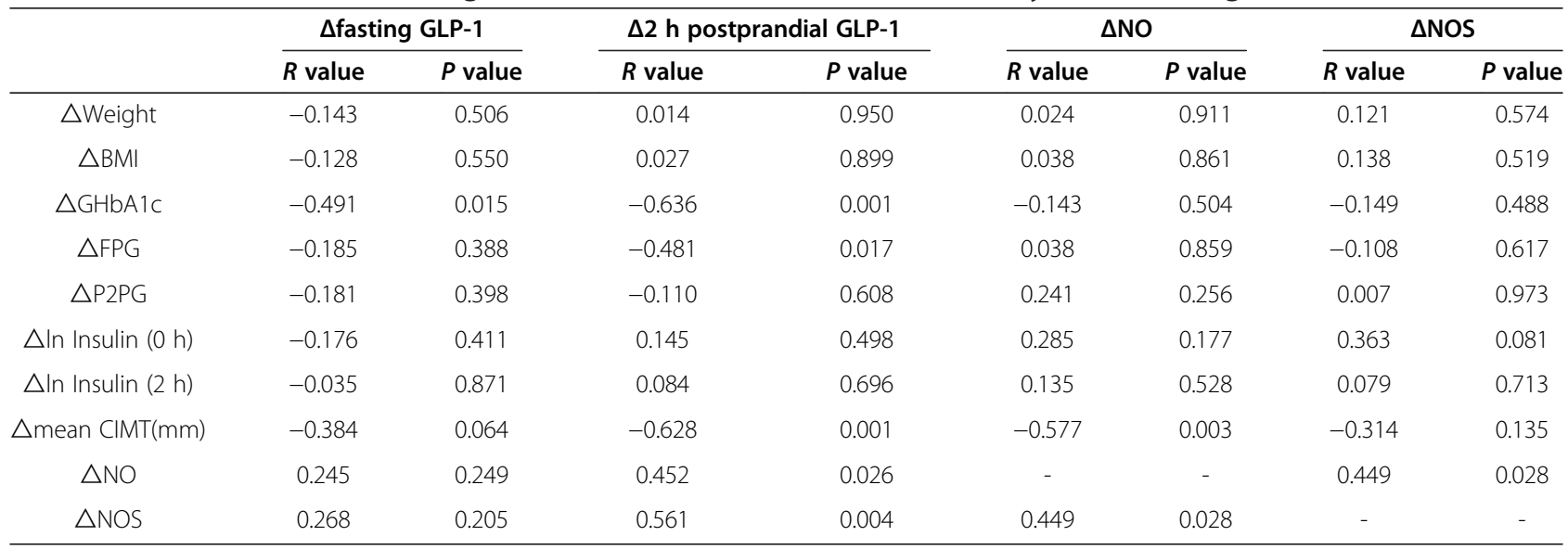

$\Delta:$ The change of values following acarbose treatment; In: natural logarithm -transformed values; BMI: body mass index; HbA1c: glycated haemoglobin A1c; FPG: fasting plasma glucose; P2PG: 2 hour postprandial plasma glucose; CIMT: carotid intima-media thickness; NO: nitric oxide; NOS: nitric oxide synthase. 
GLP-1 levels have been reported $[6,7,16,17]$. The reason that previous studies did not conclusively demonstrate the relationship between fasting GLP-1 and acarbose treatment may be due to the short treatment periods that were tested.

In theory, GLP-1 can stimulate insulin secretion and inhibit the generation of glucagon. However, our data indicate the level of postprandial insulin is significantly reduced $(P<0.05)$ following acarbose treatment and that fasting insulin levels are marginally reduced $(p=0.064)$, even in the patients with increased GLP-1 levels. Furthermore, the increased levels of GLP-1 were not correlated with the change in insulin levels $(p>0.05)$. It is known that several factors regulate insulin secretion and that glucose is the most important nutrient secretagogue. The delayed digestion of carbohydrates and cleavage of oligosaccharides by AGIs results in undigested carbohydrates reaching the lower portions of the small intestine and stimulating GLP-1 secretion. This intestinal hormone delays the emptying of the stomach, reduces glucagon secretion, and regulates insulin secretion, which in fact is dependent on blood glucose concentrations. This effect may in part explain why long-term treatment with acarbose results in a reduction in not only postprandial but also fasting blood glucose concentrations $[7,21]$. Thus, reduced blood glucose concentrations following acarbose treatment may result in (i) markedly lower stimulation of insulin synthesis and insulin secretion and (ii) decreased insulin resistance-induced hyperinsulinemia [22].

\section{Effects of acarbose on NO, NOS activity and CIMT}

As an endothelium-derived vasodilator, $\mathrm{NO}$ has been demonstrated to play a crucial role in the development of vascular complications via the regulation of blood flow and various antiatherosclerotic actions $[9,10]$. CIMT is a widely accepted indicator of subclinical atherosclerosis burden, with higher values being associated with an adverse cardiovascular prognosis. Consequently, CIMT has also been proposed to be a surrogate end point for therapeutic interventions that aim to lower the atherosclerotic burden [23,24]. In this study, we also demonstrated that both serum NO levels and NOS activity are significantly higher following acarbose treatment in the subjects whose postprandial GLP-1 was increased $(\mathrm{P}<0.05)$. Moreover, the increase in $2 \mathrm{~h}$ postprandial GLP-1 levels was (i) positively correlated with changes in NO levels and NOS activity ( $R$ values: 0.452 and 0.561 , respectively; $\mathrm{P}<0.05$ ) and (ii) negatively correlated with the change in the mean CIMT ( $\mathrm{R}$ value -0.669 ; $\mathrm{P}<0.05)$. It has been reported that GLP-1 participates in the upregulation of the activity and protein expression of NOS in human umbilical vein endothelial cells [25] and improves endothelial dysfunction in patients with
T2D and coronary heart disease [26]. What's more, serum levels of NO metabolites may be a simple, safe, convenient and reliable method for the evaluation of visceral fat accumulation in clinical diagnostic screening [27]. Several clinical studies have shown GLP-1 analogue liraglutide, alone or in combination with insulin, has produced meaningful long-term weight loss, diminished abdominal obesity and significantly improved eating behavior in patients with T2D compared with insulin treatment alone [28,29], which might be beneficial to improving endothelial dysfunction.

In a recent animal study, it has reported that orally administered voglibose, another AGI, protects the myocardium against ischemia-reperfusion injury through the stimulation of GLP-1 receptors, the activation of PI3K-Akt endothelial NOS pathways, and the opening of mitochondrial KATP channels in rabbits after 30 minutes of coronary occlusion and 48 hours of reperfusion [12]. In the present study, the observed changes in CIMT were not significantly different pre- and post-acarbose treatment. In fact, several studies have demonstrated that AGIs treatment is associated with a significant reduction the risk of cardiovascular events in populations with IGT and T2D [5,6,30]. A recent randomized comparable study has shown that AGI, miglitol, can reduce visceral fat accumulation and cardiovascular risk factors in subjects with metabolic syndrome [31]. Combination of miglitol and DPP-4 inhibitor sitagliptin can reduce postprandial glucose fluctuation and stabilize blood glucose levels [32], which may benefit to delaying atherosclerosis [3]. In a subgroup study of the STOPNIDDM trial, for which the progression of CIMT was the primary objective, the annual progression of CIMT in the placebo group was 0.014 , whereas this value was $0.007 \mathrm{~mm}(\mathrm{p}<0.01)$ in the acarbose group after 3.3 years of follow-up [33]. While we did not observe that CIMT was significantly decreased with elevated GLP-1 or NO levels, although the changes of CIMT were negatively correlated with changes of fasting, postprandial GLP-1 and NO in the present study ( $R$ values: $-0.436,-0.669$ and -0.573 , respectively; $\mathrm{P}<0.05$ ). One possible reason for this result may be due to the brief period of the study. Twenty-four weeks is perhaps too short a period over which to observe changes in CIMT.

\section{Study limitations}

The present study has several limitations. First, it is a non-randomized controlled study. Having a placebo arm may have strengthened our study further. What's more, only 24 patients finished in the study and the sample size is small, which might be a reason that we didn't observe significant change of NO level and NOS activity although postprandial GLP-1 increment is closely correlated with increment of NO levels and NOS activity after 24-week 
acarbose treatment. So, further large and randomized controlled study is needed.

\section{Conclusions}

24 weeks of acarbose treatment in newly diagnosed patients with T2D is associated with increased levels of both fasting and postprandial GLP-1. Moreover, increased GLP-1 levels increase NO secretion and NOS activity, potentially explaining the beneficial role of acarbose in preventing cardiovascular disease in these patients.

\section{Abbreviations}

AGl: Alpha-glucosidase inhibitor; BMI: Body mass index; CCA: Common carotid artery; CIMT: Carotid intima-media thickness; CV: Coefficient of variation; DPP-4: Dipeptidyl peptidase-4; ELISA: Enzyme-linked immunoassay; FPG: Fasting plasma glucose; GHbA1c: Glycated hemoglobin A1c; GLP-1: Glucagon-like peptide 1; IGT: Impaired glucose tolerance; NIDDM: Noninsulin-Dependent Diabetes Mellitus; NO: Nitric oxide; NOS: Nitric oxide synthase; P2PG: 2 h postprandial plasma glucose; T2D: Type 2 diabetes.

\section{Competing interests}

The authors declare that they have no conflicts of interest.

\section{Authors' contributions}

Zheng MY and Chang BC acquired and analyzed data, and wrote the manuscript. Chen LM conceived of the study, analyzed data and reviewed the manuscript. Zhou HT carried out Carotid ultrasonography measurements. Shan $C Y, X U$ YG, Wang $Y$ and Ren $H Z$ acquired and researched data. All authors read and approved the final manuscript.

\section{Acknowledgements}

We acknowledge the assistance of investigators and all subjects for participants in this study. This work was supported by the National Nature Science Foundation of China (No.81173428 and 81200612) and Tianjin Municipal Natural Science Foundation of China (No. 30971175).

Received: 22 March 2013 Accepted: 1 May 2013

Published: 4 May 2013

\section{References}

1. Stamler J, Vaccaro O, Neaton JD, Wentworth D: Diabetes, other risk factors, and 12-yr cardiovascular mortality for men screened in the Multiple Risk Factor Intervention Trial. Diabetes Care 1993, 16:434-444.

2. Hypertion in Diabetes Study(HDS), I: Prevalence of hypertension in newly presenting type 2 diabetic patients and the association with risk factors for cardiovascular and diabetic complications. J Hypertens 1993, 11:309-317.

3. Aronson D, Rayfield EJ: How hyperglycemia promotes atherosclerosis: molecular mechanisms. Cardiovasc Diabetol 2002, 1:1.

4. Kitada S, Otsuka Y, Kokubu N, Kasahara Y, Kataoka Y, Noguchi T, Goto Y, Kimura G, Nonogi H: Post-load hyperglycemia as an important predictor of long-term adverse cardiac events after acute myocardial infarction: a scientific study. Cardiovasc Diabetol 2010, 9:75.

5. Hanefeld M, Cagatay M, Petrowitsch T, Neuser D, Petzinna D, Rupp M: Acarbose reduces the risk for myocardial infarction in type 2 diabetic patients: metaanalysis of seven long-term studies. Eur Heart J 2004, 25:10-16.

6. Chiasson JL, Josse RG, Gomis R, Hanefeld M, Karasik A, Laakso M: STOPNIDDM Trial Research Group. Acarbose treatment and the risk of cardiovascular disease and hypertension in patients with impaired glucose tolerance: the STOP-NIDDM trial. JAMA 2003, 290:486-494.

7. Qualmann C, Nauck MA, Holst JJ, Orskov C, Creutzfeldt W: Glucagon-like peptide 1 (17-36 amide) secretion in response to luminal sucrose from the upper and lower gut: a study using aglucosidase inhibition (acarbose). Scand J Gastroenterol 1995, 30:892-896.

8. Seifarth C, Bergmann J, Holst JJ, Ritzel R, Ritzel R, Schmiegel W, Nauck MA: Prolonged and enhanced secretion of glucagon-like peptide 1(7-36 Amide) after oral sucrose due to a-glucosidase inhibition (acarbose) in type 2 diabetic patients. Diabet Med 1998, 15:485-491.
9. Bauer $V$, Sotnikova R: Nitric oxide - the endothelium-derived relaxing factor and its role in endothelial functions. Gen Physiol Biophys 2010, 29:319-340.

10. Gresele P, Migliacci R, Arosio E, Bonizzoni E, Minuz P, Violi F: NCX 4016-X-208 Study Group. Effect on walking distance and atherosclerosis progression of a nitric oxide-donating agent in intermittent claudication. J Vasc Surg 2012, 56(6):1622-1628.

11. Ban K, Noyan-Ashraf MH, Hoefer J, Bolz SS, Drucker DJ, Husain M: Cardioprotective and vasodilatory actions of glucagon-like peptide 1 receptor are mediated through both glucagon-like peptide 1 receptordependent and -independent pathways. Circulation 2008, 117:2340-2350.

12. Iwasa M, Kobayashi H, Yasuda S, Kawamura I, Sumi S, Yamada Y, Shiraki T, Yamaki T, Ushikoshi H, Aoyama T, Nishigaki K, Takemura G, Fujiwara T, Fujiwara $\mathrm{H}$, Minatoguchi $\mathrm{S}$ : Antidiabetic drug voglibose is protective against ischemia-reperfusion injury through glucagon-like peptide 1 receptors and the phosphoinositide 3-kinase-Akt-endothelial nitric oxide synthase pathway in rabbits. J Cardiovasc Pharmacol 2010 Jun, 55(6):625-634

13. von Sarnowski B, Lüdemann J, Völzke H, Dörr M, Kessler C, Schminke U: Common carotid intima-media thickness and Framingham risk score predict incident carotid atherosclerotic plaque formation: longitudinal results from the study of health in Pomerania. Stroke 2010, 41:2375-2377.

14. Polak JF, Person SD, Wei GS, Godreau A, Jacobs DR Jr, Harrington A, Sidney S, O'Leary DH: Segment-specific associations of carotid intima-media thickness with cardiovascular risk factors: the Coronary Artery Risk Development in Young Adults (CARDIA) study. Stroke 2010, 41:9-15.

15. Alberti KG, Zimmet PZ: Definition, diagnosis and classification of diabetes mellitus and its complications. Part 1: diagnosis and classification of diabetes mellitus provisional report of a WHO consultation. Diabet Med 1998, 15(7):539-553.

16. Enç FY, Imeryüz N, Akin L, Turoğlu T, Dede F, Haklar G, Tekeşin N, Bekiroğlu N, Yeğen BC, Rehfeld JF, Holst JJ, Ulusoy NB: Inhibition of gastric emptying by acarbose is correlated with GLP-1 response and accompanied by CCK release. Am J Physiol Gastrointest Liver Physiol 2001, 281(3):G752-763.

17. DeLeon MJ, Chandurkar V, Albert SG, Mooradian AD: Glucagon-like peptide-1 response to acarbose in elderly type 2 diabetic subjects. Diabetes Res Clin Pract 2002 May, 56(2):101-106.

18. Kusunoki Y, Katsuno T, Myojin M, Miyakoshi K, Ikawa T, Matsuo T, Ochi F, Tokuda M, Murai K, Miuchi M, Hamaguchi T, Miyagawa JI, Namba M: Effect of additional administration of acarbose on blood glucose fluctuations and postprandial hyperglycemia in patients with type 2 diabetes mellitus under treatment with alogliptin. Endocr $J 2012$ [Epub ahead of print].

19. Nauck M, Stöckmann F, Ebert R, Creutzfeldt W: Reduced incretin effect in type 2 (non-insulin-dependent) diabetes. Diabetologia 1986 Jan, 29(1):46-52.

20. Lugari R, Dei Cas A, Ugolotti D, Finardi L, Barilli AL, Ognibene C, Luciani A, Zandomeneghi R, Gnudi A: Evidence for early impairment of glucagonlike peptide 1-induced insulin secretion in human type 2 (non insulindependent) diabetes. Horm Metab Res 2002 Mar, 34(3):150-154.

21. Göke B, Fuder H, Wieckhorst $G$, Theiss $U$, Stridde E, Littke T, Kleist P, Arnold $R$, Lücker PW: Voglibose is an efficient alpha-glucosidase inhibitor and mobilizes the endogenous GLP-1 reserve. Digestion 1995, 56:493-501.

22. 25 Rosak C, Hofmann U, Paulwitz O: Modification of beta-cell response to different postprandial blood glucose concentrations by prandial repaglinide and combined acarbose/repaglinide application. Diabetes Nutr Metab 2004, 17(3):137-142.

23. O'Leary DH, Polak JF, Kronmal RA, Manolio TA, Burke GL, Wolfson SK Jr: Carotid-artery intima and media thickness as a risk factor for myocardial infarction and stroke in older adults. Cardiovasular Health Study Collaborative Research Group. N Engl J Med 1999, 340:14-22.

24. Lorenz MW, Markus HS, Bots ML, Rosvall M, Sitzer M: Prediction of clinical cardiovascular events with carotid intima-media thickness: a systematic review and meta-analysis. Circulation 2007, 115:459-467.

25. Ding $L$, Zhang J: Glucagon-like peptide-1 activates endothelial nitric oxide synthase in human umbilical vein endothelial cells. Acta Pharmacol Sin 2012 Jan, 33(1):75-81.

26. Nyström T, Gutniak MK, Zhang Q, Zhang F, Holst JJ, Ahrén B, Sjöholm A Effects of glucagon-like peptide- 1 on endothelial function in type 2 diabetes patients with stable coronary artery disease. Am J Physiol Endocrinol Metab 2004 Dec, 287(6):E1209-1215. 
27. Fujita K, Wada K, Nozaki Y, Yoneda M, Endo H, Takahashi H, Kirikoshi H, Inamori M, Saito S, Nakajima A: Serum nitric oxide metabolite as a biomarker of visceral fat accumulation: clinical significance of measurement for nitrate/nitrite. Med Sci Monit 2011 Feb 25, 17(3):CR123-131.

28. Fujishima Y, Maeda N, Inoue K, Kashine S, Nishizawa H, Hirata A, Kozawa J, Yasuda T, Okita K, Imagawa A, Funahashi T, Shimomura I: Efficacy of liraglutide, a glucagon-like peptide-1 (GLP-1) analogue, on body weight, eating behavior, and glycemic control, in Japanese obese type 2 diabetes. Cardiovasc Diabetol 2012 Sep 14, 11:107.

29. Li CJ, Li J, Zhang QM, Lv L, Chen R, Lv CF, Yu P, Yu DM: Efficacy and safety comparison between liraglutide as add-on therapy to insulin and insulin dose-increase in Chinese subjects with poorly controlled type 2 diabetes and abdominal obesity. Cardiovasc Diabetol 2012 Nov 15, 11:142.

30. Hanefeld M, Schaper F, Koehler C: Effect of acarbose on vascular disease in patients with abnormal glucose tolerance. Cardiovasc Drugs Ther 2008 Jun, 22(3):225-231.

31. Shimabukuro M, Higa M, Yamakawa K, Masuzaki H, Sata M: Miglitol, aglycosidase inhibitor, reduces visceral fat accumulation and cardiovascular risk factors in subjects with the metabolic syndrome: $\mathrm{A}$ randomized comparable study. Int J Cardiol 2012. Epub ahead of print.

32. Kishimoto M, Noda M: A pilot study of the efficacy of miglitol and sitagliptin for type 2 diabetes with a continuous glucose monitoring system and incretin-related markers. Cardiovasc Diabetol 2011 Dec 22, 10:115.

33. Hanefeld M, Chiasson JL, Koehler C, Henkel E, Schaper F, TemelkovaKurktschiev T: Acarbose slows progression of intimamedia thickness of the carotid arteries in subjects with impaired glucose tolerance. Stroke 2004, 35:1073-1078.

doi:10.1186/1475-2840-12-73

Cite this article as: Zheng et al: Effects of 24-week treatment with acarbose on glucagon-like peptide 1 in newly diagnosed type 2 diabetic patients: a preliminary report. Cardiovascular Diabetology 2013 $12: 73$.

\section{Submit your next manuscript to BioMed Central and take full advantage of:}

- Convenient online submission

- Thorough peer review

- No space constraints or color figure charges

- Immediate publication on acceptance

- Inclusion in PubMed, CAS, Scopus and Google Scholar

- Research which is freely available for redistribution 